\title{
Ozone-induced nasal hyperresponsiveness to tachykinins in guinea pigs
}

\author{
Ching-Yin Ho M.D., Ph.D.,* Ching-Ting Tan M.D., Ph.D.,\# Hung-Huey Tsai Ph.D.§ $§$ and \\ Yu Ru Kou Ph.D.II
}

\begin{abstract}
Objective: To assess role of hydroxyl radials in the ozone-induced upper airway hyper-responsiveness to tachykinins.

Methods: A prospective, controlled, animal model $(n=96)$ was performed. Half of them exposed to air $(A$-group, placebo) and the other half exposed to $3 \mathrm{ppm}$ ozone (O-group) for $2 \mathrm{~h}$. Two hours post air/ozone exposure, animals were anesthetized and equally randomized to be pretreated with one of the three treatments, including saline vehicle, dimethylthiourea (DMTU; $500 \mathrm{mg} / \mathrm{kg} \mathrm{m}$, a hydroxyl radical scavenger), or phosphoramidon (Phos; $2 \mathrm{mg} / \mathrm{kg}$, an inhibitor for neutral endopeptidase). Ten minutes after pretreatment, half of the animals in each group were i.v. injected with capsaicin (2 $\mu \mathrm{g} / \mathrm{kg}$ ), and the other half were i.v. injected with substance P (10 $\mu \mathrm{g} / \mathrm{kg}$ ) to produce Evans blue dye extravasation.

Results: Nasal exudative response to capsaicin or substance P in O-group was found to be significantly greater than that in A-group. This ozone-induced nasal airway hyperresponsiveness was largely prevented by DMTU. Phosphoramidon produced a similar nasal airway hyperresponsiveness in the A-group, but failed to alter ozone-induced nasal airway hyperresponsiveness in O-group. In sharp contrast, only substance $P$, but not capsaicin, produced a laryngeal exudative response in the A-group, which was similar to that in the O-group. The laryngeal exudative response to substance P was not significantly affected by DMTU or Phos.

Conculsion: In the guinea-pig model, hydroxyl radicals play a vital role in the development of ozone-induced nasal airway hyperresponsiveness to tachykinins. It is possibly mediated through the suppressive action of ozone on the tachykinin degradation.
\end{abstract}

(Am J Rhinol 22, 463-467, 2008; doi: 10.2500/ajr.2008.22.3208)

Key words: Neutral endopeptidase, oxygen radicals, ozone, phosphoramidon, substance P, tachykinins, upper airway hyperreactivity

O zone is a major pollutant in urban areas and its ambient concentration is associated with the occurrence of asthma. ${ }^{1,2,3,4}$ Consequently, many animal studies have been conducted to investigate the pathophysiological mechanisms underlying ozone-induced lower airway hyperreactivity.5,6 However, $\sim 40 \%$ of inhaled ozone is taken up in the nasal passages in healthy human subjects. ${ }^{7}$ The upper airway includes the nose and larynx. They have a close anatomic relationship and yet possess quite distinct physiologic regulations.8,9,10,11 Upper airway hyperreactivity may lead to sneezing, rhinorrhea, nasal obstruction, cough, and laryngeal spasm resulting in an increase in airway resistance to respiratory flow. Can ozone induce upper airway hyperreactivity? If it does, is it clinically significant?

Airway C-fiber afferents are chemosensitive sensory nerve endings that play an important role in the reflex regulation of airway functions. ${ }^{12,13}$ Their nerve endings contain tachykinins, a family of proinflammatory neuropeptides. The release of tachykinins may cause various pathophysiological consequences including vasodilation, plasma exudation, and bronchoconstric-

From the *Department of Otolaryngology, Veterans General Hospital-Taipei and National Yang-Ming University, \#Department of Otolaryngology, National Taiwan University Hospital, and National Taiwan University College of Medicine, §College of Oral Medicine, Taipei Medical University, and MInstitute of Physiology, School of Medicine, National Yang-Ming University, Taipei 11221, Taiwan

This study was 91-204, VGH 93-184, NSC 90-2314-B-075-107, NSC. Supported by VGH 3-2314-B-075-028.

Address correspondence and reprint requests to Ching-Yin Ho, M.D., Ph.D., at Department of Otolaryngology, Veterans General Hospital-Taipei, No. 201, Sec. 2, Shi Pai Rd. Taipei 11211, Taiwan

E-mail address: cyho@vghtpe.gov.tw

Copyright (C) 2008, OceanSide Publications, Inc., U.S.A. tion. ${ }^{14,15,16,17,18}$ Released tachykinins are mainly degraded by neutral endopeptidase. Ozone exposure has been shown to enhance the excitabilities of airway C-fiber nerve endings ${ }^{19}$ and inhibit airway neutral endopeptidase. ${ }^{20,21}$ Both actions may cause excess tachykinins in airway tissues. Thus, dysfunction of airway C-fiber afferents and inactivation of neutral endopeptidase have been largely implicated in the ozone-induced lower airway hyperreactivity. ${ }^{19,22,23,24}$ Furthermore, because ozone is an oxidant pollutant, its ability to induce lower airway hyperreactivity is linked to the effects of oxygen radicals. ${ }^{25}$ Although airway C-fiber afferents are known to innervate the upper airway, $^{26}$ the possible involvement of these pathophysiological mechanisms in the ozone-induced upper airway hyperreactivity remains to be investigated.

The present study was conducted in guinea pigs to investigate whether ozone exposure may augment nasal and laryngeal exudative and edematous responses to endogenous and exogenous tachykinins, and if so, to assess the role of hydroxyl radicals and neutral endopeptidase in this ozone-induced upper airway hyperreactivity. To accomplish these objectives, capsaicin and substance $\mathrm{P}$ were employed to induce nasal and laryngeal exudative responses. The former drug stimulates C-fiber afferents to cause the release of endogenous tachykinins, whereas the latter is an exogenous tachykinin.

\section{MATERIALS AND METHODS}

\section{Generation of Ozone and Ozone Exposure}

Ozone was generated using ultraviolet lamp (model 03V1-0, Orec, Akron, OH). The main airflow was then turbu- 
lently mixed with a small flow and routed to a 24-L Plexiglas exposure chamber. The air/ozone flow was $2 \mathrm{~L} / \mathrm{min}$ in the exposure box. The ozone concentration inside the chamber was monitored by an ultraviolet monitor (model 1003-AH, Dasibi, Glendale, CA) and its accuracy was calibrated by the potassium iodide method. Male Hartley guinea pigs (body weight, $367 \pm 12 \mathrm{~g} ; n=96$ ) were exposed to either clean air or $3.0 \mathrm{ppm}$ ozone for a 2-hour period, according to our previous work $^{19}$ After exposure, animals were removed from the exposure chamber and held in an animal cage for one hour for the subsequent experiments.

\section{Animal Preparation}

Animals were anesthetized with an i.p. injection of $\alpha$-chloralose (100 mg/kg; Sigma, St. Louis, MO) and urethane (500 $\mathrm{mg} / \mathrm{kg}$; Sigma). The carotid artery and jugular vein were cannulated for recording arterial blood pressure and for i.v. administration of pharmacological agents, respectively. During the course of the experiments, supplemental doses of $\alpha$-chloralose (20 mg/kg/h) and urethane (100 mg/kg/h) were administered to maintain the abolition of pain reflexes induced by pinching the animal's hindpaw. The animal was fixed in a supine position and the trachea was cannulated below the larynx with a short tracheal cannula via a tracheotomy, through which the animal breathed spontaneously. Animal preparation took $\sim 1 \mathrm{hr}$. Throughout the experiment, the body temperature of the animal was maintained at $\sim 36^{\circ} \mathrm{C}$ by means of a servo heating blanket. All protocols were in accordance with the guidelines for the care and use of laboratory animals published by the National Institutes of Health, Bethesda, MD and were approved by the Committee of the National Science Council, Taipei, Taiwan.

\section{Measurements of Plasma Exudation and Tissue Edema}

The magnitude of plasma exudation was quantified by measuring the extravasation of Evans blue dye, using the aforementioned method. ${ }^{27}$ In brief, Evans blue dye $(25 \mathrm{mg} /$ $\mathrm{kg}$ ) was injected i.v. 5 minutes before injecting capsaicin or substance P. Five minutes later, the thorax was quickly opened. The left ventricle was opened and the systemic circulation was perfused with $200 \mathrm{~mL}$ of saline at a pressure of $120 \mathrm{mmHg}$ to remove the intravascular dye.

After vascular perfusion, the tissues of the nasal cavity, paranasal sinus, and whole larynx were excised and each was then separated into two parts. Tissue Evans blue dye was extracted by incubation in $1.5 \mathrm{~mL}$ of formamide (Sigma) at $40^{\circ} \mathrm{C}$ for 24 hours and its concentration was measured by light absorbance (Multiscan spectrophotometer, U-100. Hitachi, Tokyo, Japan) at $620 \mathrm{~nm}$. The tissue content of Evans blue dye was calculated by interpolation on a standard curve of dye concentrations in the range of $0.05 \mu \mathrm{g} / \mathrm{mL}$ and was expressed as ng of dye/mg of tissue.

\section{Pharmacological Agents}

A stock solution of capsaicin ( $500 \mu \mathrm{g} / \mathrm{mL}$; Sigma) was prepared in a vehicle of $10 \%$ Tween $80,10 \%$ ethanol, and $80 \%$ saline. The injected capsaicin solution $(500 \mu \mathrm{g} / \mathrm{mL})$ was prepared daily by diluting the stock solution with isotonic saline. Dimethylthiourea (500 mg/mL; Sigma), phosphoramidon (2 $\mathrm{mg} / \mathrm{mL}$; Sigma) and substance P (10 $\mu \mathrm{g} / \mathrm{mL}$; Sigma) were prepared using isotonic saline.

\section{Experimental Procedures}

A total of 96 male guinea pigs were evenly divided into 6 groups. Animals were first exposed to air $(n=48)$ or ozone $(n=48)$ for a 2-hour period. Two hours later, animals were anesthetized and pretreated with saline vehicle, dimethylthiourea (DMTU; $500 \mathrm{mg} / \mathrm{kg}$; a hydroxyl radical scavenger), or phosphoramidon (Phos; $2 \mathrm{mg} / \mathrm{kg}$; an inhibitor for neutral endopeptidase) to study the possible role of hydroxyl radical and endopeptidase in the ozone-induced airway hyperreactivity. Thus, the animals were divided into 6 treatment groups, Air+Saline, Ozone+Saline, Air+DMTU, Ozone+DMTU, Air +Phos, and Ozone+Phos groups. Ten minutes after pretreatment, half of the animals in each group were i.v. injected with capsaicin (CAP; $2 \mu \mathrm{g} / \mathrm{kg}$, a stimulator to increase endogenous tachykinins), and the other half were i.v. injected with substance P (SP; $10 \mu \mathrm{g} / \mathrm{kg}$, an exogenous tachykinin) to produce Evans blue dye extravasation.

\section{Statistical Analysis}

Results of exudative responses of nasal and laryngeal tissues were analyzed by one-way analysis of variance adjusted for multiple comparisons by Duncan's method when appropriate. A value of $p<0.05$ was considered significant. All data were presented as means $\pm \mathrm{SE}$.

\section{RESULTS}

In the Air+Saline group, challenge of either capsaicin (Fig. 1) or substance P (Fig. 2) produced plasma exudation in nasal tissues as evidenced by a significant increase in Evans blue concentration. In the Ozone+Saline group, challenge of the same dose of either capsaicin (Fig. 1) or substance P (Fig. 2) produced an augmented nasal exudative response that was significantly greater than the response from the Air+Saline group. The Ozone+DMTU group had significantly greater nasal exudative response to challenge of capsaicin (Fig. 1) and substance P (Fig. 2) compared to the Air+Saline group, but was similar compared to the Ozone+Saline group. The nasal exudative responses to challenge of either capsaicin (Fig. 1) or substance P (Fig. 2) in both the Air+Phos and Ozone+Phos groups were significantly greater than the Air+Saline and the Ozone+DMTU group, but they were not significantly different from the Ozone+Saline group.

In contrast to the results obtained from nasal tissues, challenge of capsaicin failed to increase Evans blue concentration of laryngeal tissues in all study groups (Fig. 3). Challenge of substance $\mathrm{P}$ produced a significant increase in Evans blue concentration of laryngeal tissues in the Air+Saline group (Fig. 4). However, the laryngeal exudative response to substance P did not vary among the Air+Saline, Ozone+Saline, Ozone+DMTU, Air+Phos, and Ozone+Phos groups (Fig. 4).

\section{DISCUSSION}

Using a guinea-pig model, we demonstrated that both capsaicin- and substance P-induced nasal exudative responses, whereas only substance $P$ caused laryngeal exudative responses. Capsaicin is known to stimulate C-fiber afferents to cause the release of endogenous tachykinins. Substance $\mathrm{P}$, in contrast, is an 


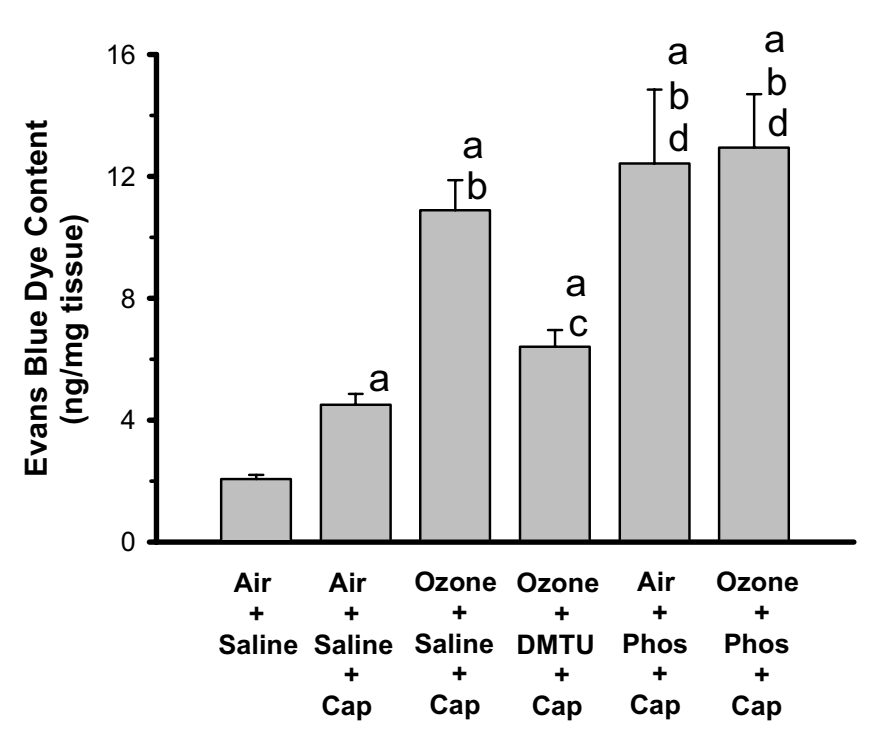

Figure 1. Evans blue dye contents of nasal tissue excited from animals receiving i.v. injection of capsaicin (Cap) after air or ozone exposure. Animals received pretreatment with saline vehicle, dimethylthiourea (DMTU), or phosphoramidan (Phos). a: Significantly different from the Air+Saline group; $b$ : Significantly different from the Air +Saline +Cap group; c: Significantly different from the Ozone+Saline+Cap group; d: Significantly different from the Ozone+DMTU+Cap group. Data in each group are means $\pm S E$ for 8 animals.

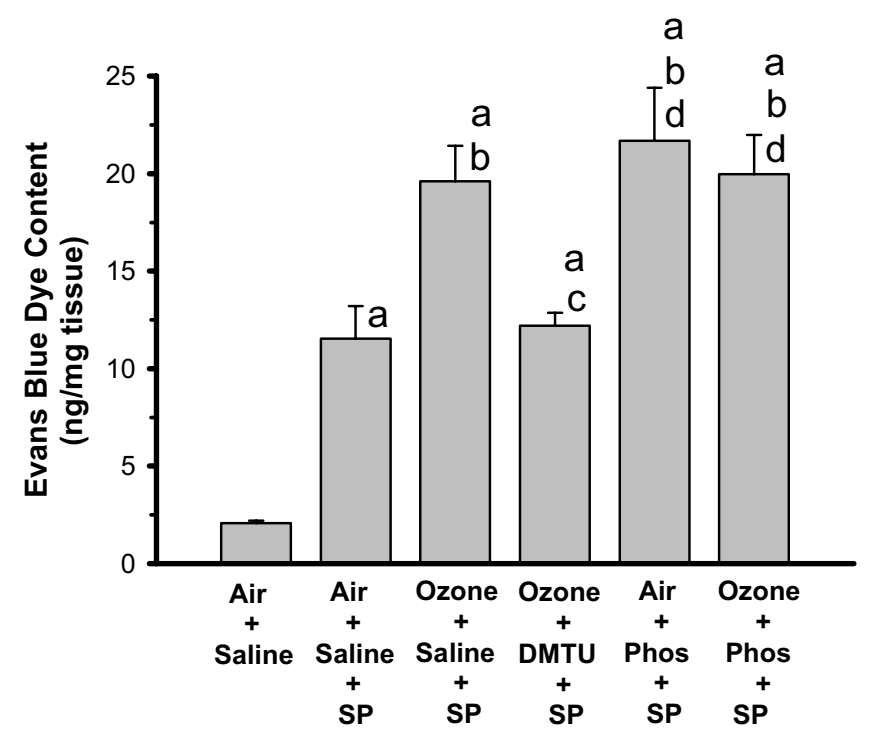

Figure 2. Evans blue dye contents of nasal tissue excited from animals receiving i.v. injection of substance $P(S P)$ after air or ozone exposure. Data in each group are means $\pm S E$ for 8 animals. See legend of Fig. 1 for detail descriptions of animal groups and statistical comparisons.

exogenous tachykinin. Ozone exposure significantly augmented nasal exudative responses to both challenges. However, it dose not have significant effect on the laryngeal exudative responses to substance $\mathrm{P}$. These results suggest that ozone exposure selec-

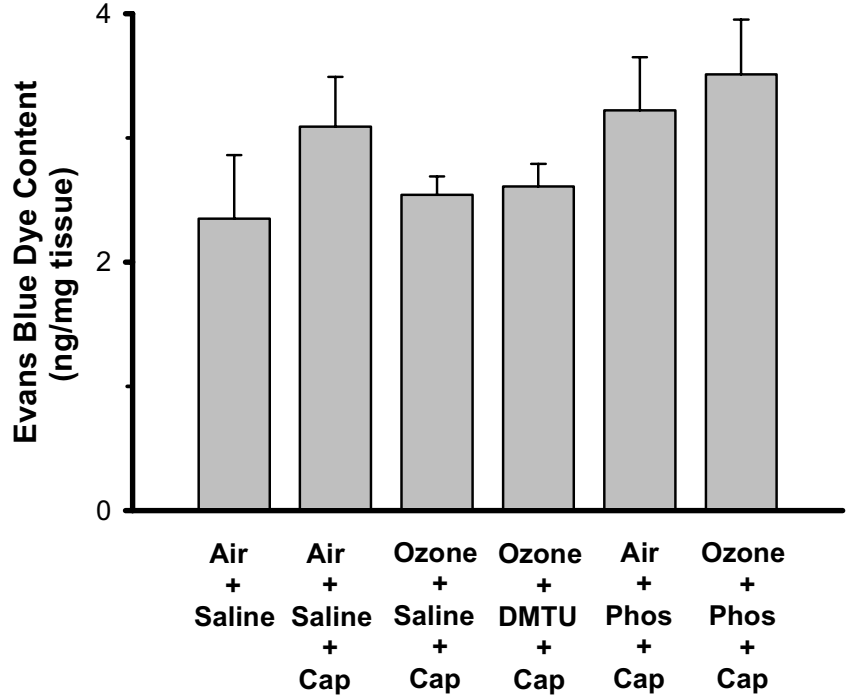

Figure 3. Evans blue dye contents of laryngeal tissue excited from animals receiving i.v. injection of capsaicin (Cap) after air or ozone exposure. See legend of Fig. 1 for detail descriptions of animal groups. No significance could be detected between any two groups. Data in each group are means $\pm S E$ for 8 animals.

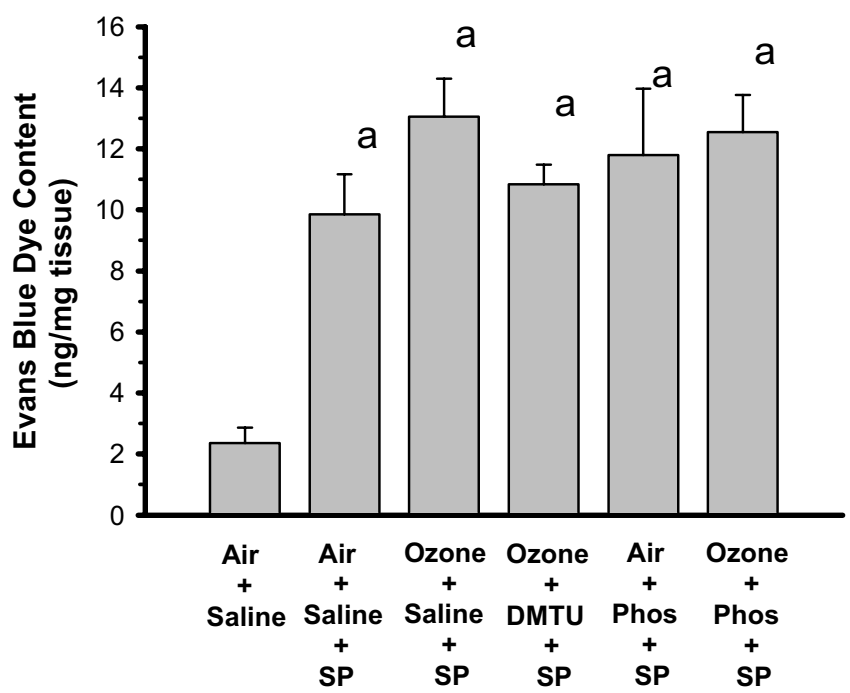

Figure 4. Evans blue dye contents of laryngeal tissue excited from animals receiving i.v. injection of substance $P(S P)$ after air or ozone exposure. See legend of Fig. 1 for detail descriptions of animal groups and statistical comparisons. Data in each group are means \pm SE for 8 animals.

tively induces nasal airway hyperresponsiveness to endogenous and exogenous tachykinins.

The exact mechanisms by which ozone could augment nasal exudative responses to capsaicin or substance $\mathrm{P}$ are unclear. Ozone is shown to increase the excitabilities of airway C-fiber nerve endings. ${ }^{19}$ It also caused airway epithelial injury, ${ }^{28,29,30}$ and the consequent epithelial desquamation may make sensory nerve endings more accessible to exogenous stimuli. Thus, the same dose of capsaicin could cause a larger release of endogenous tachykinins from the sensitized C-fiber 
nerve endings and a greater exudative response in the Ozone + Saline group compared to the Air+Saline group. In addition, ozone is shown to inhibit neutral endopeptidase, ${ }^{20,21}$ which may result in excess tachykinin in nasal tissues and augmented exudative responses to either capsaicin or substance P. In this study, pretreatment with phosphoramidon, an inhibitor for neutral endopeptidase, produced augmented nasal exudative responses in the Air+Saline group that mimicked the effect of ozone on nasal exudative responses in the Ozone+Saline group. It did not further increase nasal exudative responses in the Ozone+Saline group. These observations provide evidence of the involvement of nasal neutral endopeptidase inhibition in the development of ozone-induced nasal airway hyperresponsiveness to tachykinins. It is found that the ozone-induced augmentation of nasal exudative responses could be totally prevented by pretreatment with dimethylthiourea, a hydroxyl radical scavenger. This finding suggests that the hydroxyl radical plays a vital role in the pathogenesis of this nasal airway hyperreactivity. This is not surprising because the hydroxyl radical has been shown to inhibit airway neutral endopeptidase. ${ }^{31,32,33,34}$ Thus, pretreatment with dimethylthiourea may lower the oxidative stress of nasal tissues after ozone exposure and prevent the inhibition of nasal neutral endopeptidase by ozone.

In this study, challenge of substance $P$ produced a significant increase in Evans blue concentration of laryngeal tissues, but challenge of capsaicin failed to increase Evans blue concentration of laryngeal tissues in the Air+Saline group. This observation shows that substance $\mathrm{P}$ activated tachykinin receptors in the laryngeal tissue, but this concentration of capsaicin could not activate laryngeal C-fibers. Furthermore, there was a different response to ozone exposure in the nose and larynx. The capsaicin- or substance P-induced nasal exudative response could be enhanced by ozone exposure. In contrast, substance P-induced laryngeal exudative response dose not significantly increase with ozone exposure. The apneic response induced by nasal chemical stimulus could be enhanced by ozone exposure, but the apneic response evoked by laryngeal chemical stimulus was inhibited by ozone exposure (data not shown). The upper airway includes the nose and larynx. Although they have a very close anatomic relationship, their physiologic regulations are quite different. Previous studies showed that laryngeal exposure to wood smoke triggers an apneic response that does not depend on laryngeal C-fiber afferents. ${ }^{35,36}$ In contrast, nasal exposure to wood smoke can evoke apneic or sniff-like responses and C-fiber afferents play an important role in this smoke-induced nasal response. ${ }^{37}$ Different pathophysiologic responses between nose and larynx is demonstrated. ${ }^{36-37}$

In summery, in the guinea-pig model, hydroxyl radicals play a vital role in the development of ozone-induced nasal airway hyperresponsiveness to tachykinins, which is possibly mediated through the suppressive action of ozone on the tachykinin degradation. Further research is needed to gain knowledge on the underline mechanisms of ozone-induced nasal hyperresponsiveness. Knowing this underlying mechanism might clarify the reasons for increasing prevalence of allergic rhinitis and the search for new therapeutic agents for allergic rhinitis.

\section{ACKNOWLEDGMENTS}

The authors thank Dr. Yu-Yun Ho for statistical consultation.

\section{REFERENCES}

1. Luttinger D, and Wilson L. A study of air pollutants and acute asthma exacerbations in urban areas: Status report. Environ Pollution 123:399-402, 2003.

2. Ross MA, Persky VW, Scheff PA, et al. Effect of ozone and aeroallergens on the respiratory health of asthmatics. Arch Environ Health 57:568-578, 2002.

3. Parnia S, Brown JL, and Frew AJ. The role of pollutants in allergic sensitization and the development of asthma. Allergy 57:1111-1117, 2002.

4. Nicolai T. Pollution, environmental factors and childhood respiratory allergic disease. Toxicology 181-182:317-321, 2002.

5. Folinsbee LJ, Horstman DH, Kehrl HR, et al. Respiratory responses to repeated prolonged exposure to $0.12 \mathrm{ppm}$ ozone. Am J Respir Crit Care Med 149:98-105, 1994.

6. Krishna MT, Mudway I, Kelly FJ, et al. Ozone, airways and allergic airways disease. Clin Exper Allergy 25:1150-1158, 1995.

7. Gerrity TR, Weaver RA, Berntsen J, et al. Extrathoracic and intrathoracic removal of $\mathrm{O} 3$ in tidal-breathing humans. J Appl Physiol 65:393-400, 1988.

8. Isaacs RS, and Sykes JM. Anatomy and physiology of the upper airway. Anesthesiol Clin North Am 20:733-745, 2002.

9. Pierce RJ, and Worsnop CJ. Upper airway function and dysfunction in respiration. Clin Exper Pharmacol Physiol 26:1-10, 1999.

10. Cole P. Physiology of the nose and paranasal sinuses. Clin Rev Allergy Immunol 16:25-54, 1998.

11. Sasaki CT, and Weaver EM. Physiology of the larynx. Am J Med 103: 9S-18S, 1997.

12. Coleridge JC, and Coleridge HM. Afferent vagal $C$ fibre innervation of the lungs and airways and its functional significance. Rev Physiol Biochem Pharmacol 99:1-110, 1984.

13. Sant'Ambrogio G. Nervous receptors of the tracheobronchial tree. Annu Rev Physiol 49:611-627, 1987.

14. Lin YS, Ho CY, Tang GJ, et al. Alleviation of wood smokeinduced lung injury by tachykinin receptor antagonist and hydroxyl radical scavenger in guinea pigs. Eur J Pharmacol 425:141-148, 2001.

15. Baluk P, Thurston G, Murphy TJ, et al. Neurogenic plasma leakage in mouse airways. Brit J Pharmacol 126:522-528, 1999.

16. Ricciardolo FL, Rado V, Fabbri LM, et al. Bronchoconstriction induced by citric acid inhalation in guinea pigs: Role of tachykinins, bradykinin, and nitric oxide. Am J Respir Crit Care Med 159:557-562, 1999.

17. Yoshihara S, Geppetti P, Linden A, et al. Tachykinins mediate the potentiation of antigen-induced bronchoconstriction by cold air in guinea pigs. J Allergy Clin Immunol 97:756760, 1996.

18. Lee LY, Lou YP, Hong JL, et al. Cigarette smoke-induced bronchoconstriction and release of tachykinins in guinea pig lungs. Respir Physiol 99:173-181, 1995.

19. Ho CY, and Lee LY. Ozone enhances excitabilities of pulmonary $C$ fibers to chemical and mechanical stimuli in anesthetized rats. J Appl Physiol 85:1509-1515, 1998.

20. Tsukagoshi H, Haddad EB, Sun J, et al. Ozone-induced airway hyperresponsiveness: Role of superoxide anions, NEP, and BK receptors. J Appl Physiol 78:1015-1022, 1995.

21. Murlas CG, Lang Z, Williams GJ, et al. Aerosolized neutral endopeptidase reverses ozone-induced airway hyperreactivity to substance P. J Appl Physiol 72:1133-1410, 1992. 
22. Fu L, Kaneko $\mathrm{T}$, Ikeda $\mathrm{H}$, et al. Tachykinins via Tachykinin NK2 receptor activation mediate ozone-induced increase in the permeability of the tracheal mucosa in guinea-pigs. Brit J Pharmacol 135:1331-1335, 2002.

23. Graham RM, Friedman M, and Hoyle GW. Sensory nerves promote ozone-induced lung inflammation in mice. Am J Respir Crit Care Med 164:307-313, 2001.

24. Tepper JS, Costa DL, Fitzgerald S, et al. Role of tachykinins in ozone-induced acute lung injury in guinea pigs. J Appl Physiol 75:1404-1411, 1993.

25. Liu L, Leech JA, Urch RB, et al. In vivo salicylate hydroxylation: A potential biomarker for assessing acute ozone exposure and effects in humans. Am J Respir Crit Care Med 156:1405-1412, 1997.

26. Sant'Ambrogio G, Tsubone H, and Sant'Ambrogio FB. Sensory information from the upper airway: Role in the control of breathing. Respir Physiol 102:1-16, 1995.

27. Evans TW, Rogers DF, Aursudkij B, et al. Inflammatory mediators involved in antigen-induced airway microvascular leakage in guinea pigs. Am Rev Respir Dis 138:395-399, 1988.

28. Campos MG, Segura P, Vargas MH, et al. O3-induced airway hyperresponsiveness to noncholinergic system and other stimuli. J Appl Physiol 73:54-61, 1992.

29. Holtzman MJ, Fabbri LM, O’Byrne PM, et al. Importance of airway inflammation for hyperresponsiveness induced by ozone. Am Rev Respir Dis 127:686-690, 1983.
30. Murlas CG, and Roum JH. Sequence of pathologic changes in the airway mucosa of guinea pigs during ozone-induced bronchial hyperreactivity. Am Rev Respir Dis 131:314-320, 1985.

31. Dusser DJ, Djokic TD, Borson DB, et al. Cigarette smoke induces bronchoconstrictor hyperresponsiveness to substance $\mathrm{P}$ and inactivates airway neutral endopeptidase in the guinea pig. Possible role of free radicals. J Clin Invest 84: 900-906, 1989.

32. Borson DB. Roles of neutral endopeptidase in airways. Am J Physiol 260:L212-L225, 1991.

33. Solway J, and Leff AR. Sensory neuropeptides and airway function. J Appl Physiol 71:2077-2087, 1991.

34. Hsu TH, Lai YL, and Kou YR. Wood smoke-induced airway hyperreactivity in guinea pigs: Time course, and role of leukotrienes and hydroxyl radical. Life Sci 66:971980, 2000.

35. Lin YS, and Kou YR. Reflex apneic response evoked by laryngeal exposure to wood smoke in rats: Neural and chemical mechanisms. J Appl Physiol 83:723-730, 1997.

36. Lin YS, Ho CY, Chang SY, et al. Laryngeal C-fiber afferents are not involved in the apneic response to laryngeal wood smoke in anesthetized rats. Life Sci 66:1695-1704, 2000.

37. Ho CY, and Kou YR. Protective and defensive airway reflexes evoked by nasal exposure to wood smoke in anesthetized rats. J Appl Physiol 88:863-870, 2000. 